\title{
Usefulness of the blood urea nitrogen-to-serum albumin ratio as a prognostic indicator of severity in acute ischemic stroke
}

\author{
Sung Jin Bae ${ }^{1}$, Sun Hwa Lee ${ }^{2}$, Seong Jong Yun ${ }^{3}$, Keon Kim ${ }^{4, *}$
}

${ }^{1}$ Department of Emergency Medicine, College of Medicine, Chung-Ang

University, 102, Heukseok-ro,

Dongjak-gu, Seoul, Republic of Korea

${ }^{2}$ Ewha Womans University Mokdong Hospital, Department of Emergency Medicine, College of Medicine, Ewha Womans University, 1071

Anyangcheon-ro, Yangcheon-gu, Seoul, Republic of Korea

${ }^{3}$ Department of Radiology, G SAM hospital, 591 Gunpo-ro, Gunpo-si, Gyeonggi-do, 15839, Republic of Korea ${ }^{4}$ Ewha Womans University Seoul Hospital, Department of Emergency Medicine, College of Medicine, Ewha Womans University, 260,

Gonghang-daero, Gangseo-gu, Seoul, 07804, Republic of Korea

\section{*Correspondence}

mikky5163@gmail.com

(Keon Kim)

\begin{abstract}
Objectives: Acute ischemic stroke (AIS) is one of the most important and major causes of mortality worldwide. In AIS patients, the blood urea nitrogen to creatinine ratio (B/C ratio) was investigated as a dehydrated biomarker in previous studies. However, the $\mathrm{B} / \mathrm{C}$ ratio can be affected by medications and past medical history. We hypothesized addition of serum albumin, which has been shown to have beneficial neuroprotective effects, could compensate for the disadvantages. In the present study, the BUN to serum albumin ratio (B/A ratio) was evaluated association with AIS patient's prognosis.

Methods: This retrospective cohort study of AIS in our hospital was conducted from February 2018 through June 2020. First, demographic and clinical data were collected and compared with the prevalence of mortality and ICU admission. Then, the $\mathrm{B} / \mathrm{C}$ ratio and the $\mathrm{B} / \mathrm{A}$ ratio were calculated. Differences in the performance between the $\mathrm{B} / \mathrm{C}$ ratio and the $\mathrm{B} / \mathrm{A}$ ratio for outcome prediction were evaluated based on the area under the curve of the receiver operating characteristic (AUROC).

Results: Among the 1,164 patients enrolled in this study, 77 (6.6\%) died during hospitalization and $467(40.1 \%)$ were admitted to ICU. Multivariate logistic regression had shown that the $\mathrm{B} / \mathrm{A}$ ratio was a significant predictor of mortality and admission to ICU. In addition, the B/A ratio was significantly higher in ICU-admitted patients and non-survivors. The AUROC of the $\mathrm{B} / \mathrm{A}$ ratio was 0.687 and the $\mathrm{B} / \mathrm{C}$ ratio was 0.533 for predicting mortality; the $\mathrm{B} / \mathrm{A}$ ratio was statistically superior to the $\mathrm{B} / \mathrm{C}$ ratio. For predicting ICU admission, the AUROC values of the $\mathrm{B} / \mathrm{A}$ ratio and the $\mathrm{B} / \mathrm{C}$ ratio were 0.567 and 0.556 , respectively, and a statistically significant difference was not observed. Conclusion: The B/A ratio is a simple and useful tool for predicting the outcomes of ischemic stroke patients.
\end{abstract}

\section{Keywords}

Stroke; Blood urea nitrogen; Albumin; Mortality; Intensive care unit; Emergency department

\section{Introduction}

Acute ischemic stroke (AIS) is one of the most common cause of mortality and long-term disability worldwide [1]. Although advanced therapies have improved in recent years and reperfusion therapies, such as intravenous thrombolysis and endovascular thrombectomy [2], in particular, were developed in the past years, the mortality and the socioeconomic burden of stroke remains significantly high [3]. In stroke patients, $20 \%-40 \%$ will experience early neurological deterioration after hospital admission and have poor outcomes $[4,5]$. In addition, complications of endovascular therapy may occur during or after the procedure and can lead to long-term disability and even fatality [6]. Therefore, quickly predicting the prognosis and applying appropriate treatment is important.

Many scoring tools have been developed to predict the severity and outcome in AIS patients. The most widely used stroke scale is the National Institutes of Health Stroke Scale (NIHSS), which has been validated for accuracy in predicting severity and prognosis $[7,8]$. However, due to many variables and the resulting relative complexity, the NIHSS can be difficult to use for non-stroke health care physicians. In addition, the NIHSS may also involve the subjective judgement of physicians. Conversely, the use of laboratory results may be required for emergency physicians to make more objective and simpler predictions regarding severity and prognosis.

In previous studies, dehydration reportedly affected the prognosis of stroke $[9,10]$. The blood urea nitrogen to creatinine ratio $(\mathrm{B} / \mathrm{C}$ ratio) in AIS had been investigated in several studies as a biomarker of dehydration status. However, the $\mathrm{B} / \mathrm{C}$ ratio has disadvantages and can be affected by medications, including diuretics, and past medical history, 
such as renal disease [9]. Therefore, we hypothesized addition of another variable can compensate for the disadvantages. Serum albumin has been shown to exert a beneficial neural protection effect as a unique multi-functional protein $[11,12]$. Consequently, lower serum albumin has been shown to be associated with worse prognosis for AIS patients in several studies $[13,14]$.

Although the prognosis of pneumonia was suggested to be associated with the BUN to serum albumin ratio (B/A ratio) $[15,16]$ in several studies, the $\mathrm{B} / \mathrm{A}$ ratio in patients with AIS has not been investigated. In this study, the association between the $\mathrm{B} / \mathrm{A}$ ratio and outcomes in AIS patients was evaluated.

\section{Methods}

\subsection{Study design}

This was a single-center, retrospective study in which the electronic medical records (EMRs) of patients diagnosed with stroke in the emergency department (ED) were used. This study was approved by the institutional review board of our hospital (IRB No: 2020-10-022), and the requirement for written informed consent was waived.

\subsection{Setting and population}

In the present study, ED patients who visited a tertiary-care academic hospital between February, 2018 and June, 2020, were investigated. The hospital is located in the metropolitan area of South Korea. The number of patients visiting the ED of this hospital ranges from 60,000-70,000 annually. Only the patients who were diagnosed with ischemic stroke in the ED were included in the present study. Ischemic stroke was diagnosed and confirmed by a neurologist and emergency physicians based on neurologic examination and radiologic confirmation. Patients younger than 18 years of age and patients who visited the ED for non-medical problems were excluded. In addition, patients with incomplete EMR data, due to discharged against medical advice, transferred to another facility, or did not perform any laboratory tests in the ED, were excluded (Fig. 1).

\subsection{Data collection and outcome measurement}

Stroke was diagnosed using computed tomography and magnetic resonance imaging in the ED. In addition, the final diagnosis was reviewed by board-certified emergency physicians or neurologist following hospital regulations. The data were obtained from the eligible patient's EMRs. Obtained data were patient demographics including sex and age; initial vital signs including mental status, blood pressure (systolic and diastolic blood pressure), pulse rate (PR), respiratory rate (RR), and body temperature; laboratory results including BUN and albumin (others are presented in Table 1), and clinical details including discharge, general ward (GW) or intensive care unit (ICU) admission, hospital length, and mortality.

The $\mathrm{B} / \mathrm{A}$ ratio was defined as the BUN value divided by the albumin value. The $\mathrm{B} / \mathrm{C}$ ratio was defined as the $\mathrm{BUN}$
TA B L E 1. Baseline characteristics of patients

(Total $\mathrm{n}=1,164)$

\begin{tabular}{|c|c|}
\hline Variable & Value* \\
\hline Age (years) & $67.7 \pm 14.7$ \\
\hline \multicolumn{2}{|l|}{ Sex } \\
\hline Male & $606(52.1)$ \\
\hline Female & $558(47.9)$ \\
\hline Systolic Blood Pressure (mmHg) & $144.0 \pm 35.7$ \\
\hline Diastolic Blood Pressure (mmHg) & $78.4 \pm 22.3$ \\
\hline Pulse rate (beats/min) & $85.3 \pm 21.9$ \\
\hline Respiratory rate (breath/min) & $19.9 \pm 3.6$ \\
\hline Body temperature $\left({ }^{\circ} \mathrm{C}\right)$ & $36.2 \pm 4.2$ \\
\hline \multicolumn{2}{|l|}{ Mental status } \\
\hline Alert & $829(71.2)$ \\
\hline Verbal response & $120(10.3)$ \\
\hline Painful response & $202(17.4)$ \\
\hline Unresponsive & $13(1.1)$ \\
\hline \multicolumn{2}{|l|}{ Laboratory test } \\
\hline White blood cell $\left(10^{9} / \mathrm{L}\right)$ & $9.3 \pm 4.7$ \\
\hline Hemoglobin $(\mathrm{g} / \mathrm{dL})$ & $13.0 \pm 2.3$ \\
\hline Hematocrit (\%) & $37.2 \pm 6.4$ \\
\hline Platelet $\left(10^{9} / \mathrm{L}\right)$ & $229.3 \pm 83.9$ \\
\hline C-reactive protein $(\mathrm{mg} / \mathrm{dL})$ & $2.8 \pm 6.2$ \\
\hline Blood urea nitrogen (mg/dL) & $22.4 \pm 20.0$ \\
\hline Creatinine $(\mathrm{mg} / \mathrm{dL})$ & $1.2 \pm 1.2$ \\
\hline $\operatorname{Albumin}(\mathrm{g} / \mathrm{dL})$ & $3.8 \pm 0.6$ \\
\hline Aspartate aminotransferase (IU/L) & $45.9 \pm 173.4$ \\
\hline Alanine aminotransferase (IU/L) & $32.3 \pm 113.3$ \\
\hline Glucose $(\mathrm{mg} / \mathrm{dL})$ & $167.3 \pm 101.4$ \\
\hline Sodium $(\mathrm{mmol} / \mathrm{L})$ & $137.1 \pm 5.9$ \\
\hline Potassium (mmol/L) & $4.0 \pm 0.7$ \\
\hline Troponin-T (ng/mL) & $0.05 \pm 0.23$ \\
\hline PT (INR) & $1.1 \pm 0.4$ \\
\hline PTT (sec) & $25.9 \pm 6.0$ \\
\hline Hospital day (days) & $18.2 \pm 24.5$ \\
\hline ICU admission & $467(40.1)$ \\
\hline In-hospital mortality & $77(6.6)$ \\
\hline BUN/Albumin ratio & $6.6 \pm 7.7$ \\
\hline BUN/Creatinine ratio & $19.6 \pm 9.3$ \\
\hline
\end{tabular}

* The values are given as mean \pm standard deviation or number (\%).

White blood cell (WBC), C-reactive protein (CRP), Blood urea nitrogen (BUN), Creatinine (Cr), Aspartate aminotransferase (AST), Alanine aminotransferase (ALT).

value divided by the creatinine value. The ICU admission group was defined as patients admitted to the ICU and the non- 


\section{Flow chart}

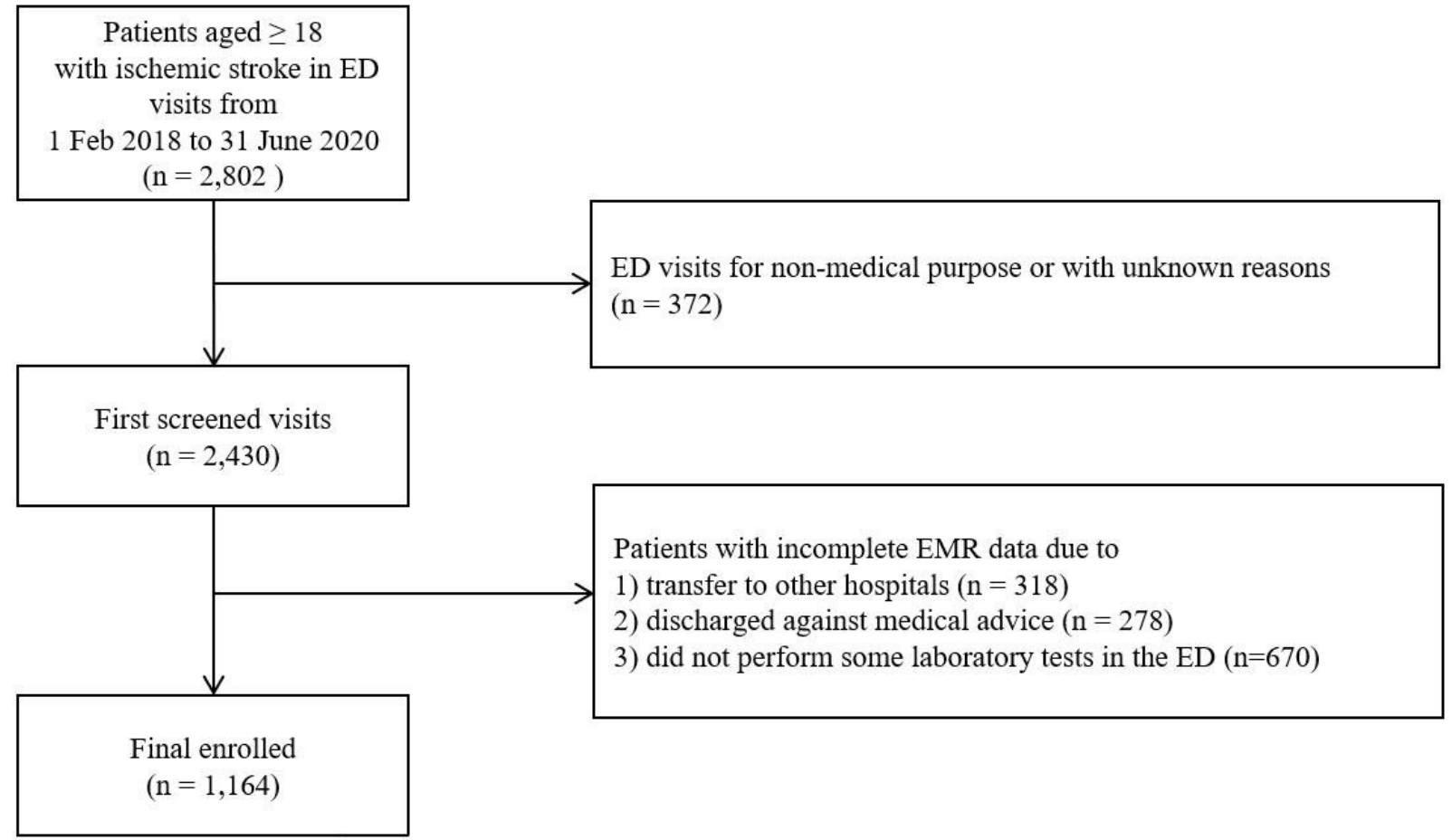

F I G U RE 1. Flow chart of patients enrolled in the study.

ICU admission group was defined as those patients discharged or admitted to the GW. The mortality group was defined as patients who died in the hospital and the non-mortality group as the discharged patients who survived.

The primary outcome was to predict in-hospital mortality. The secondary outcome was to predict need for ICU in preparation for GW admission or discharge.

\subsection{Statistical analysis}

Continuous variables are presented as the mean with standard deviation (SD), and categorical variables as count (percentage). Baseline characteristics were analyzed using the student $t$-test for continuous variables and Pearson's chi-square test for categorical variables. Multivariate logistic regression analysis was used to assess the association between each factor and mortality or need for ICU admission. Differences in the performance between the $\mathrm{B} / \mathrm{C}$ ratio and the $\mathrm{B} / \mathrm{A}$ ratio for predicting outcome were evaluated with the area under the curve of receiver operating characteristic (AUROC). An AUROC range in $0.8-0.9$ is considered good, range in $0.7-0.8$ adequate, and range in $0.6-0.7$ poor [17]. The optimal cut-off values of each ratio were presented by the Youden Index of ROC curves. The sensitivity and specificity were described by the proposed optimal cut-off value [18]. Data were statistically analyzed using SPSS 26.0 (SPSS Inc., Chicago, IL, USA). MedCalc Statistical Software version 19 (MedCalc Software bvba, Ostend, Belgium) with Delong method was used to determine the AUROC curve. The $P$-value $<0.05$ was considered statistically significant.

\section{Results}

\subsection{Characteristics of the population}

This study included 1,164 patients. The baseline characteristics, and clinical details of patients are summarized in Table 1. The mean age \pm SD of the patients was $67.7 \pm 14.7$ years and 606 patients $(52.1 \%)$ were male. The number of patients with altered mental status was 335 (28.8\%). There were 467 patients $(40.1 \%)$ admitted to the ICU and 77 patients $(6.6 \%)$ died in the hospital during clinical process.

\subsection{Comparison of clinical factors for in-hospital mortality}

The results for vital signs showed significantly lower blood pressure and body temperature in the mortality group compared with the non-mortality group. The percentage of patients with an altered mental status was significantly greater in the mortality group than in the non-mortality group. In laboratory tests, the mortality group had significantly higher WBC, AST, ALT, CRP, glucose, PT (INR), and PTT levels. The mortality group had significantly lower hemoglobin levels than the nonmortality group. The $\mathrm{B} / \mathrm{A}$ ratio was significantly higher in the mortality group than in the non-mortality group. In addition, the $\mathrm{B} / \mathrm{C}$ ratio was higher in the mortality group but without statistical significance. The multivariate logistic regression analysis showed an altered mental status, PT (INR), and B/A ratio were significant independent factors for predicting mortality (Table 2). 
TA B L E 2. Logistic regression analysis of mortality predictors

\begin{tabular}{|c|c|c|c|c|c|c|}
\hline \multirow{3}{*}{ Variable } & \multicolumn{2}{|c|}{ Univariate analysis $^{a}$} & & \multicolumn{3}{|c|}{ Multivariate analysis $^{b}$} \\
\hline & Non-mortality group & Mortality group & & & & \\
\hline & $n=1087$ & $\mathbf{n}=\mathbf{7 7}$ & P-value & OR & B & P-value \\
\hline Age (years) & $67.5 \pm 14.7$ & $70.4 \pm 15.2$ & 0.093 & & & \\
\hline Sex; Male & $564(51.9)$ & $42(54.5)$ & 0.652 & & & \\
\hline Systolic Blood Pressure (mmHg) & $145.2 \pm 33.6$ & $126.3 \pm 54.9$ & 0.004 & $1.008(0.997,1.020)$ & 0.008 & 0.309 \\
\hline Diastolic Blood Pressure (mmHg) & $79.3 \pm 21.4$ & $66.0 \pm 30.6$ & $<0.001$ & $0.984(0.965,1.003)$ & -0.016 & 0.074 \\
\hline Pulse rate (beats/min) & $85.1 \pm .20 .8$ & $87.8 \pm 34.0$ & 0.492 & & & \\
\hline Respiratory rate (breath/min) & $19.9 \pm 3.1$ & $19.6 \pm 7.3$ & 0.730 & & & \\
\hline Body temperature $\left({ }^{\circ} \mathrm{C}\right)$ & $36.4 \pm 3.5$ & $34.1 \pm 9.4$ & 0.038 & $0.970(0.928,1.014)$ & -0.030 & 0.180 \\
\hline Altered mental status & $279(25.7)$ & $56(72.7)$ & $<0.001$ & $5.482(2.926,10.27)$ & 1.701 & $<0.001$ \\
\hline \multicolumn{7}{|l|}{ Laboratory test } \\
\hline White blood cell $\left(10^{9} / \mathrm{L}\right)$ & $9.2 \pm 4.5$ & $11.9 \pm 6.5$ & 0.001 & $1.002(0.945,1.062)$ & 0.002 & 0.949 \\
\hline Hemoglobin $(\mathrm{g} / \mathrm{dL})$ & $13.0 \pm 2.3$ & $12.2 \pm 2.8$ & 0.013 & $1.008(0.898,1.131)$ & 0.008 & 0.892 \\
\hline Hematocrit $(\%)$ & $37.3 \pm 6.2$ & $35.5 \pm 7.9$ & 0.058 & & & \\
\hline Platelet $\left(10^{9} / \mathrm{L}\right)$ & $230.6 \pm 80.3$ & $211.5 \pm 123.9$ & 0.190 & & & \\
\hline C-reactive protein (mg/dL) & $2.5 \pm 5.8$ & $6.7 \pm 9.3$ & 0.001 & $1.029(0.989,1.069)$ & 0.028 & 0.155 \\
\hline Aspartate aminotransferase (IU/L) & $41.9 \pm 173.4$ & $102.5 \pm 163.3$ & 0.002 & $1.000(0.999,1.001)$ & 0.000 & 0.595 \\
\hline Alanine aminotransferase (IU/L) & $30.6 \pm 113.6$ & $56.4 \pm 107.0$ & 0.045 & $0.999(0.993,1.005)$ & -0.001 & 0.782 \\
\hline Glucose (mg/dL) & $164.6 \pm 96.9$ & $205.1 \pm 147.5$ & 0.020 & $1.000(0.998,1.002)$ & 0.000 & 0.886 \\
\hline Sodium $(\mathrm{mmol} / \mathrm{L})$ & $137.0 \pm 5.5$ & $138.4 \pm 10.2$ & 0.222 & & & \\
\hline Potassium (mmol/L) & $4.0 \pm 0.6$ & $4.1 \pm 1.0$ & 0.129 & & & \\
\hline Troponin-T (ng/mL) & $0.04 \pm 0.21$ & $0.13 \pm 0.38$ & 0.050 & & & \\
\hline PT (INR) & $1.1 \pm 0.3$ & $1.3 \pm 0.7$ & 0.004 & $1.731(1.071,2.798)$ & 0.549 & 0.025 \\
\hline PTT (sec) & $25.7 \pm 5.5$ & $28.7 \pm 10.1$ & 0.011 & & & \\
\hline Hospital day (days) & $10.8 \pm 15.5$ & $29.3 \pm 30.6$ & 0.218 & & & \\
\hline ICU admission & $407(37.4)$ & $60(77.9)$ & $<0.001$ & & & \\
\hline BUN/Albumin ratio & $6.2 \pm 6.7$ & $12.4 \pm 14.6$ & $<0.001$ & $1.032(1.009,1.055)$ & 0.031 & 0.006 \\
\hline BUN/Creatinine ratio & $19.5 \pm 8.9$ & $22.2 \pm 13.5$ & 0.084 & & & \\
\hline
\end{tabular}

${ }^{a}$ The values are given as mean \pm standard deviation or number (\%).

${ }^{b}$ Data in parentheses are $95 \%$ confidence intervals, conducted on variables with a P value of $<0.05$ on univariate analysis. OR odds ratio, $B$ regression coefficient.

Boldface typed means statistical significance $(P<0.05)$.

\subsection{Comparison of clinical factors for ICU admission}

The ICU admission group was statistically significantly younger than the non-ICU admission group. The ICU admission group had a statistically significant lower body temperature compared with the non-ICU admission group. The ICU admission group had a statistically significant greater percentage of patients with altered mental status than the non-ICU admission group. The ICU admission group had significantly higher WBC, AST, ALT, CRP, and glucose than the non-ICU admission group. The $\mathrm{B} / \mathrm{A}$ ratio and the $\mathrm{B} / \mathrm{C}$ ratio were statistically significantly higher in the ICU admission group than in the non-ICU admission group. The multivariate logistic regression analysis showed age, altered mental status, $\mathrm{WBC}$, potassium, and the $\mathrm{B} / \mathrm{A}$ ratio were significant independent factors for predicting ICU admission (Table 3).

\subsection{Predictive performance of the $\mathrm{B} / \mathrm{A}$ ratio compared with the $\mathrm{B} / \mathrm{C}$ ratio}

The AUROC for predicting in-hospital mortality is shown in Fig. 2. The AUROC was 0.687 (95\% confidence interval, CI, 0.659-0.713) for the $\mathrm{B} / \mathrm{A}$ ratio and 0.533 (95\% CI, 0.5040.562 ) for the $\mathrm{B} / \mathrm{C}$ ratio. Statistically significant difference was observed between the two ratios $(0.154 ; 95 \% \mathrm{CI}, 0.0954-$ $0.212 ; P<0.001)$. The cut-off value of the $\mathrm{B} / \mathrm{A}$ ratio for predicting mortality was 5.25 (sensitivity: $64.9 \%$, specificity: $67.8 \%$ ). The cut-off value of the $\mathrm{B} / \mathrm{C}$ ratio for predicting mortality was 26.2 (sensitivity: $29.9 \%$, specificity: $84.8 \%$ ).

The AUROC for predicting the need for ICU admission is 
TA B L E 3. Logistic regression analysis of ICU admission predictors

\begin{tabular}{|c|c|c|c|c|c|c|}
\hline \multirow[t]{3}{*}{ Variable } & \multicolumn{2}{|c|}{ Univariate analysis $^{a}$} & \multicolumn{4}{|c|}{ Multivariate analysis ${ }^{b}$} \\
\hline & \multirow{2}{*}{$\begin{array}{c}\text { Non-ICU } \\
\text { admission group } \\
n=697\end{array}$} & \multirow{2}{*}{$\begin{array}{c}\text { ICU } \\
\text { admission group } \\
n=467\end{array}$} & \multirow[b]{2}{*}{ P-value } & \multirow[b]{2}{*}{ OR } & \multirow[b]{2}{*}{ B } & \multirow[b]{2}{*}{ P-value } \\
\hline & & & & & & \\
\hline Age (years) & $68.9 \pm 14.6$ & $65.9 \pm 14.7$ & 0.001 & $0.976(0.964,0.988)$ & -0.025 & $<0.001$ \\
\hline Sex; Male & $371(53.2)$ & $235(50.3)$ & 0.331 & & & \\
\hline Systolic Blood Pressure (mmHg) & $144.5 \pm 30.5$ & $143.2 \pm 42.2$ & 0.547 & & & \\
\hline Diastolic Blood Pressure (mmHg) & $78.3 \pm 19.5$ & $78.5 \pm 26.0$ & 0.923 & & & \\
\hline Pulse rate (beats/min) & $84.4 \pm 18.8$ & $86.7 \pm 25.8$ & 0.094 & & & \\
\hline Respiratory rate (breath/min) & $19.7 \pm 2.1$ & $20.0 \pm 5.0$ & 0.225 & & & \\
\hline Body temperature $\left({ }^{\circ} \mathrm{C}\right)$ & $36.5 \pm 2.6$ & $35.8 \pm 5.8$ & 0.008 & $0.971(0.925,1.018)$ & -0.03 & 0.226 \\
\hline Altered mental status & $99(14.2)$ & $236(50.5)$ & $<0.001$ & $5.004(3.411,7.340)$ & 1.61 & $<0.001$ \\
\hline \multicolumn{7}{|l|}{ Laboratory test } \\
\hline White blood cell $\left(10^{9} / \mathrm{L}\right)$ & $8.2 \pm 4.0$ & $11.0 \pm 5.1$ & $<\mathbf{0 . 0 0 1}$ & $1.088(1.045,1.132)$ & 0.084 & $<0.001$ \\
\hline Hemoglobin $(\mathrm{g} / \mathrm{dL})$ & $13.0 \pm 2.2$ & $13.0 \pm 2.5$ & 0.962 & & & \\
\hline Hematocrit $(\%)$ & $37.2 \pm 6.1$ & $37.2 \pm 6.8$ & 0.913 & & & \\
\hline Platelet $\left(10^{9} / \mathrm{L}\right)$ & $228.3 \pm 80.1$ & $230.8 \pm 89.5$ & 0.622 & & & \\
\hline C-reactive protein $(\mathrm{mg} / \mathrm{dL})$ & $2.2 \pm 5.3$ & $3.8 \pm 7.4$ & $<0.001$ & $1.001(0.970,1.034)$ & 0.001 & 0.933 \\
\hline Aspartate aminotransferase (IU/L) & $35.2 \pm 50.6$ & $61.9 \pm 265.9$ & 0.032 & $1.001(0.997,1.005)$ & 0.001 & 0.545 \\
\hline Alanine aminotransferase (IU/L) & $25.0 \pm 24.9$ & $43.4 \pm 175.9$ & 0.026 & $0.999(0.993,1.006)$ & -0.001 & 0.821 \\
\hline Glucose $(\mathrm{mg} / \mathrm{dL})$ & $152.5 \pm 81.6$ & $189.3 \pm 122.1$ & $<0.001$ & $1.001(1.000,1.003)$ & 0.001 & 0.067 \\
\hline Sodium (mmol/L) & $137.0 \pm 5.5$ & $137.3 \pm 6.6$ & 0.382 & & & \\
\hline Potassium (mmol/L) & $4.0 \pm 0.6$ & $3.9 \pm 0.8$ & 0.034 & $0.679(0.525,0.877)$ & -0.388 & 0.003 \\
\hline Troponin-T (ng/mL) & $0.04 \pm 0.26$ & $0.06 \pm 0.17$ & 0.312 & & & \\
\hline PT (INR) & $1.1 \pm 0.3$ & $1.1 \pm 0.5$ & 0.008 & $1.011(0.631,1.621)$ & 0.011 & 0.964 \\
\hline PTT (sec) & $25.9 \pm 5.7$ & $25.8 \pm 6.3$ & 0.619 & & & \\
\hline Hospital day (days) & $10.8 \pm 15.5$ & $29.3 \pm 30.6$ & $<0.001$ & & & \\
\hline In-Hospital Mortality & $17(2.4)$ & $60(12.8)$ & $<0.001$ & & & \\
\hline BUN/Albumin ratio & $5.6 \pm 5.7$ & $8.1 \pm 9.7$ & $<\mathbf{0 . 0 0 1}$ & $1.029(1.000,1.060)$ & 0.029 & 0.004 \\
\hline BUN/Creatinine ratio & $18.8 \pm 8.1$ & $20.8 \pm 10.7$ & 0.001 & $1.011(0.993,1.030)$ & 0.011 & 0.256 \\
\hline
\end{tabular}

${ }^{a}$ The values are given as mean \pm standard deviation or number (\%).

${ }^{b}$ Data in parentheses are $95 \%$ confidence intervals, conducted on variables with a $P$ value of $<0.05$ on univariate analysis.

OR odds ratio, $B$ regression coefficient.

Boldface typed means statistical significance $(P<0.05)$.

shown in Fig. 3. The AUROC for the B/A ratio was 0.567 (95\% CI, 0.537-0.595) and for the $\mathrm{B} / \mathrm{C}$ ratio 0.556 (95\% CI, $0.527-0.585)$. The $\mathrm{B} / \mathrm{A}$ ratio was superior to the $\mathrm{B} / \mathrm{C}$ ratio but without statistically significant difference $(0.0105 ; 95 \% \mathrm{CI}$, $0.0222-0.0432 ; P=0.530$ ). The cut-off value for the $\mathrm{B} / \mathrm{A}$ ratio was 6.7 (sensitivity: $29.4 \%$, specificity: $82.9 \%$ ) and for the $\mathrm{B} / \mathrm{C}$ ratio 17.9 (sensitivity: $55.2 \%$, specificity: $54.4 \%$ ), which shows higher specificity although lower sensitivity.

\section{Discussion}

In the present study, we demonstrated that the $\mathrm{B} / \mathrm{A}$ ratio an independent prognostic factor for mortality and need for ICU admission. In addition, in multivariate logistic regression analysis, factors affecting both mortality and ICU admission among the various predictors included altered mental status and the $\mathrm{B} / \mathrm{A}$ ratio but not $\mathrm{B} / \mathrm{C}$ ratio.

The B/A ratio was shown an independent factor for predicting mortality due to pneumonia. Recently, some studies have demonstrated the $\mathrm{B} / \mathrm{A}$ ratio is a useful tool for predicting mortality for other diseases [19, 20]. However, in some studies, high BUN and low albumin levels were shown to affect poor outcomes in ischemic stroke patients. In previous studies, chronic kidney disease (CKD) was suggested a risk factor for cardiovascular disease and associated with poor outcome in AIS patients [21, 22]. However, the prognostic role of CKD for the outcome in AIS patients differed depending on the renal function biomarker used, such as eGFR, creatinine, $\mathrm{B} / \mathrm{C}$ ratio, and proteinuria $[22,23]$. Shoujiang You et al. 


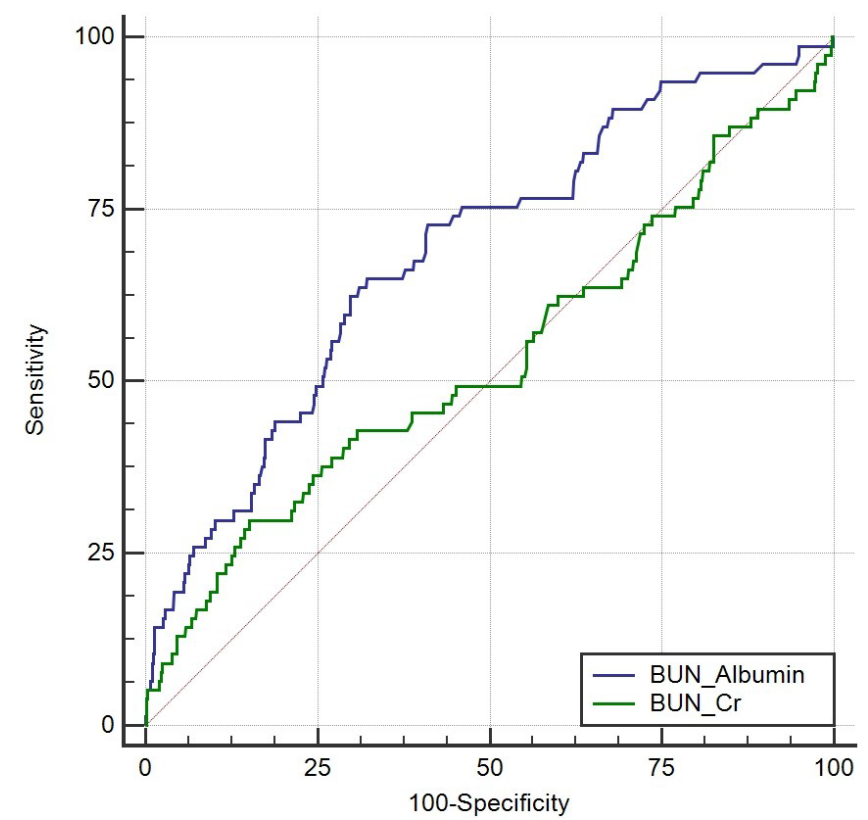

FIGURE 2. The Area under the curve of the receiver operating characteristic (AUROC) curve for predicting inhospital mortality using the $B / A$ and $B / C$ ratios. The two predicting tools were significantly different when compared (0.154; 95\% CI, 0.0954-0.212; $P<0.001)$.

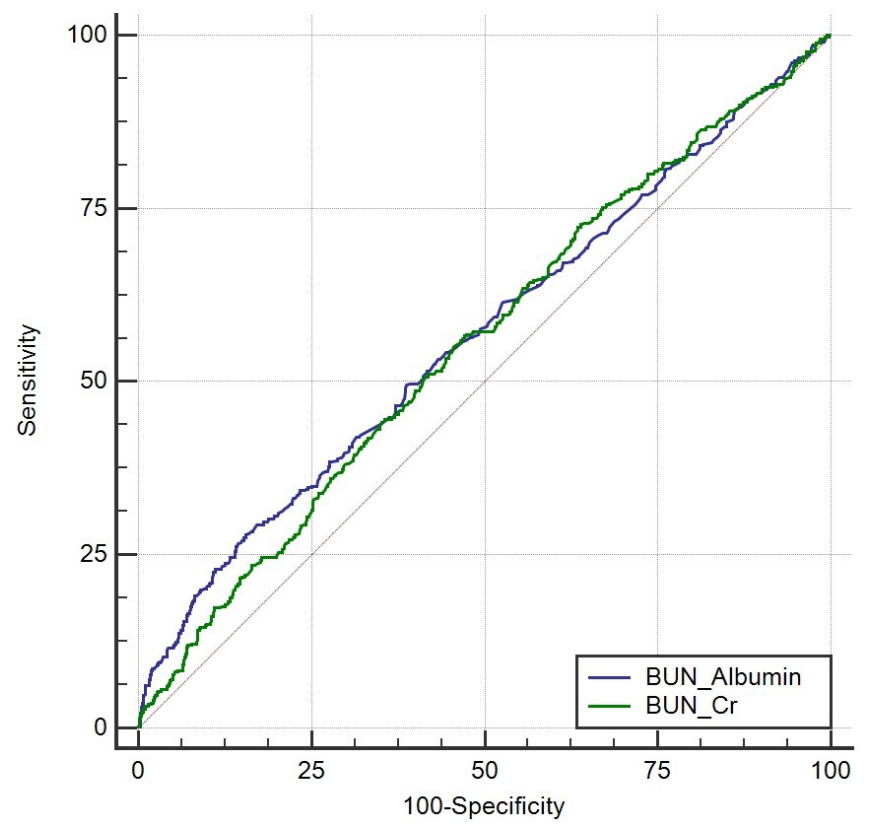

FIGURE 3. The Area under the curve of the receiver operating characteristic (AUROC) for predicting ICU admission using the $B / A$ and $B / C$ ratios. The two predicting tools were not significantly different when compared $(0.0105$; 95\% CI, 0.0222-0.0432; $P=0.530$ ).

demonstrated that BUN was significantly associated with poor outcomes in AIS patients, and the prognostic role of BUN was superior to other indicators such as eGFR, Cr, or B/C ratio [24]. The precise mechanism regarding the relationship between high BUN and poor outcomes in AIS patients is unclear, however, several hypotheses have been proposed. BUN may reflect hydration status. Appropriate hydration status leads to adequate blood flow, ensuring oxygen supply to organs. Blood flow to organs was shown significantly reduced in the dehydration state [25]. In addition, cardiac output decreases in the dehydration state, thus, higher BUN reflects hemodynamic instability and decreases blood flow to the brain [26].

In addition, serum albumin has often been identified as a hydration or nutrition marker. Furthermore, in studies on animal models, serum albumin had a neuro-protective effect in AIS $[27,28]$. In several studies, serum albumin was proven a useful predictor of outcome in AIS patients [13, 14]. Several hypotheses have explained the relationship between serum albumin and stroke prognosis. First, after ischemic injury, albumin may penetrate through the blood-brain barrier (BBB) into the brain tissue. Then, albumin is taken up by normal morphologic cortical neurons [29], possibly explaining the neuroprotective effect exerted by serum albumin. Second, serum albumin plays a role in the transport of hormones, drugs, amino acids, and free fatty acids in the blood. Serum albumin can modulate the colloid osmotic pressure in blood and lead to improved blood perfusion of the brain [30]. Third, serum albumin may be important for inhibiting platelet aggregation. In several studies, hypoalbuminemia was shown associated with high vascular thrombotic risk [31,32].

Degradation of renal function is common in AIS patients and affects outcomes due to pathological interactions between the kidney and brain [33, 34]. Hypoalbuminemia is common among CKD patients and is associated with mortality in CKD patients [35]. The mechanism underlying is unclear. It was thought that chronic inflammation in patients with CKD has resulted in a decrease in albumin synthesis or an increase in decomposition [36]. Thus, the increase in the $\mathrm{B} / \mathrm{A}$ ratio due to the increase in serum BUN level and the decrease in serum albumin level not only reflects dehydration status, but also indicates a degradation of renal function and it can predict poor outcomes for AIS patients.

\section{Limitations}

The present study had several limitations. First, the study was conducted at a single center, thus, selection bias may have existed due to the small sample size. Caution should be used in generalizing the study results to stroke patients. Further multicentered, prospectively designed studies may be needed. Second, only patients diagnosed with stroke and confirmed based on brain imaging were included in the study group; however, a potential selection bias for patient inclusion may have existed. Third, the mortality sample size was relatively smaller than the number of survivors, which may be insufficient to identify all predictors.

\section{Conclusions}

The $\mathrm{B} / \mathrm{A}$ ratio has good predictive performance for the prognosis of AIS patients. Monitoring serum albumin and BUN levels and calculating the $\mathrm{B} / \mathrm{A}$ ratio may be helpful for identifying stroke patients at high risk of mortality and ICU admission. 


\section{AUTHOR CONTRIBUTIONS}

Study concept and design: K Kim. Acquisition of subjects and/or data: S J Bae: S H Lee. Preparation of manuscript: S J Bae: S J Yun. Analysis data: S J Bae: S H Lee. All authors reviewed, revised, and approved the manuscript for submissions. Study supervision: K Kim.

\section{ETHICS APPROVAL AND CONSENT TO PARTICIPATE}

The study was approved by the institutional review board of Ewha Womans University Mokdong Hospital, and the requirement for written informed consent was waived (IRB No: 202010-022).

\section{ACKNOWLEDGMENT}

We would like to acknowledge our emergency department staffs for their support.

\section{FUNDING}

The authors received no financial support for the research, authorship, and/or publication of this article.

\section{CONFLICT OF INTEREST}

The authors have no conflicts of interest to declare that are relevant to the content of this article.

\section{DATA AVAILABILITY}

The data used to support the findings of this study are available from the corresponding author upon request.

\section{REFERENCES}

[1] Benjamin EJ, Virani SS, Callaway CW, Chamberlain AM, Chang AR, Cheng S, et al. Heart disease and stroke statistics-2018 update: a report from the American Heart Association. Circulation. 2018; 137: e67-e492.

[2] Bhaskar S, Stanwell P, Cordato D, Attia J, Levi C. Reperfusion therapy in acute ischemic stroke: dawn of a new era? BMC Neurology. 2018; 18 : 8 .

[3] Wang G, Zhang Z, Ayala C, Dunet DO, Fang J, George MG. Costs of hospitalization for stroke patients aged 18-64 years in the United States. Journal of Stroke and Cerebrovascular Diseases. 2014; 23: 861-868.

[4] Thanvi B, Treadwell S, Robinson T. Early neurological deterioration in acute ischaemic stroke: predictors, mechanisms and management. Postgraduate Medical Journal. 2008; 84: 412-417.

[5] Siegler JE, Martin-Schild S. Early Neurological Deterioration (END) after stroke: the END depends on the definition. International Journal of Stroke. 2011; 6: 211-212.

[6] Balami JS, White PM, McMeekin PJ, Ford GA, Buchan AM. Complications of endovascular treatment for acute ischemic stroke: prevention and management. International Journal of Stroke. 2018; 13: 348-361.

[7] Adams HP, Davis PH, Leira EC, Chang K-, Bendixen BH, Clarke WR, et al. Baseline NIH Stroke Scale score strongly predicts outcome after stroke: a report of the Trial of Org 10172 in Acute Stroke Treatment (TOAST). Neurology. 1999; 53: 126-131.

[8] Meyer BC, Hemmen TM, Jackson CM, Lyden PD. Modified National Institutes of Health Stroke Scale for use in stroke clinical trials: prospective reliability and validity. Stroke. 2002; 33: 1261-1266.
[9] Schrock JW, Glasenapp M, Drogell K. Elevated blood urea nitrogen/creatinine ratio is associated with poor outcome in patients with ischemic stroke. Clinical Neurology and Neurosurgery. 2012; 114: 881884.

[10] Deng L, Wang C, Qiu S, Bian H, Wang L, Li Y, et al. Association between blood urea nitrogen-to-creatinine ratio and three-month outcome in patients with acute ischemic stroke. Current Neurovascular Research. 2019; 16: 166-172.

[11] Ginsberg MD, Palesch YY, Hill MD, Martin RH, Moy CS, Barsan WG, et al. High-dose albumin treatment for acute ischaemic stroke (ALIAS) Part 2: a randomised, double-blind, phase 3, placebo-controlled trial. The Lancet Neurology. 2013; 12: 1049-1058.

[12] Chen J, Fredrickson V, Ding Y, Cheng H, Wang N, Ling F, et al. Enhanced neuroprotection by local intra-arterial infusion of human albumin solution and local hypothermia. Stroke. 2013; 44: 260-262.

[13] Zhang Q, Lei Y, Wang Q, Jin Y, Fu R, Geng H, et al. Serum albumin level is associated with the recurrence of acute ischemic stroke. The American Journal of Emergency Medicine. 2016; 34: 1812-1816.

[14] Babu MS, Kaul S, Dadheech S, Rajeshwar K, Jyothy A, Munshi A. Serum albumin levels in ischemic stroke and its subtypes: correlation with clinical outcome. Nutrition. 2013; 29: 872-875.

[15] Ryu S, Oh SK, Cho SU, You Y, Park JS, Min JH, et al. Utility of the blood urea nitrogen to serum albumin ratio as a prognostic factor of mortality in aspiration pneumonia patients. The American Journal of Emergency Medicine. 2020; S0735-6757(20)30118-2.

[16] Viasus D, Garcia-Vidal C, Simonetti A, Manresa F, Dorca J, Gudiol F, et al. Prognostic value of serum albumin levels in hospitalized adults with community-acquired pneumonia. The Journal of Infection. 2014; 66: 415-423.

[17] Hajian-Tilaki K. Receiver Operating Characteristic (ROC) curve analysis for medical diagnostic test evaluation. Caspian Journal of Internal Medicine. 2013; 4: 627-635.

[18] Perkins NJ, Schisterman EF. The inconsistency of "optimal" cutpoints obtained using two criteria based on the receiver operating characteristic curve. American Journal of Epidemiology. 2006; 163: 670-675.

[19] Zou X, Feng D, Wu W, Yang H, Zhang T. Blood urea nitrogen to serum albumin ratio independently predicts 30-day mortality and severity in patients with Escherichia coli bacteraemia. Medicina ClíNica. 2020; S0025-7753(20)30638-2. (In Spanish)

[20] Akahane J, Ushiki A, Kosaka M, Ikuyama Y, Matsuo A, Hachiya T, et al. Blood urea nitrogen-to-serum albumin ratio and a-DROP are useful in assessing the severity of pneumocystis pneumonia in patients without human immunodeficiency virus infection. Journal of Infection and Chemotherapy. 2020; S1341-321X(20)30452-9.

[21] Putaala J, Haapaniemi E, Gordin D, Liebkind R, Groop P, Kaste M, et al. Factors associated with impaired kidney function and its impact on longterm outcome in young ischemic stroke. Stroke. 2011; 42: 2459-2464.

[22] Kim J, Song TJ, Song D, Yoo J, Baek JH, Lee HS, et al. Prognostic value of urine dipstick proteinuria on mortality after acute ischemic stroke. Atherosclerosis. 2016; 253: 118-123.

[23] Ovbiagele B, Schwamm LH, Smith EE, Grau-Sepulveda MV, Saver JL, Bhatt DL, et al. Patterns of care quality and prognosis among hospitalized ischemic stroke patients with chronic kidney disease. Journal of the American Heart Association. 2014; 3: e000905.

[24] You S, Zheng D, Zhong C, Wang X, Tang W, Sheng L, et al. Prognostic significance of blood urea nitrogen in acute ischemic stroke. Circulation Journal. 2019; 82: 572-578.

[25] González-Alonso J, Calbet JAL, Nielsen B. Muscle blood flow is reduced with dehydration during prolonged exercise in humans. The Journal of Physiology. 1998; 513: 895-905.

[26] Aronson D, Mittleman MA, Burger AJ. Elevated blood urea nitrogen level as a predictor of mortality in patients admitted for decompensated heart failure. The American Journal of Medicine. 2004; 116: 466-473.

[27] Belayev L, Busto R, Zhao W, Clemens JA, Ginsberg MD. Effect of delayed albumin hemodilution on infarction volume and brain edema after transient middle cerebral artery occlusion in rats. Journal of Neurosurgery. 1997; 87: 595-601.

[28] Belayev L, Zhao W, Pattany PM, Weaver RG, Huh PW, Lin B, et al. Diffusion-weighted magnetic resonance imaging confirms marked 
neuroprotective efficacy of albumin therapy in focal cerebral ischemia. Stroke. 1998; 29: 2587-2599.

[29] Remmers M, Schmidt-Kastner R, Belayev L, Lin B, Busto R, Ginsberg MD. Protein extravasation and cellular uptake after high-dose humanalbumin treatment of transient focal cerebral ischemia in rats. Brain Research. 1999; 827: 237-242.

[30] Belayev L, Liu Y, Zhao W, Busto R, Ginsberg MD. Human albumin therapy of acute ischemic stroke: marked neuroprotective efficacy at moderate doses and with a broad therapeutic window. Stroke. 2001; 32: 553-560.

[31] Djoussé L, Rothman KJ, Cupples LA, Levy D, Ellison RC. Serum albumin and risk of myocardial infarction and all-cause mortality in the Framingham Offspring Study. Circulation. 2002; 106: 2919-2924.

[32] Lionaki S, Derebail VK, Hogan SL, Barbour S, Lee T, Hladunewich M, et al. Venous thromboembolism in patients with membranous nephropathy. Clinical Journal of the American Society of Nephrology. 2012; 7: 43-51.

[33] Saeed F, Adil MM, Khursheed F, Daimee UA, Branch LA, Vidal GA, et al. Acute renal failure is associated with higher death and disability in patients with acute ischemic stroke: analysis of nationwide inpatient sample. Stroke. 2014; 45: 1478-1480.

[34] Toyoda K, Ninomiya T. Stroke and cerebrovascular diseases in patients with chronic kidney disease. The Lancet Neurology. 2014; 13: 823-833.

[35] Singh T, Astor BC, Waheed S. End-stage renal disease patients with low serum albumin: is peritoneal dialysis an option? Peritoneal Dialysis International. 2019; 39: 562-567.

[36] Minatoguchi S, Nomura A, Imaizumi T, Sasaki S, Ozeki T, Uchida $\mathrm{D}$, et al. Low serum albumin as a risk factor for infection-related inhospital death among hemodialysis patients hospitalized on suspicion of infectious disease: a Japanese multicenter retrospective cohort study. Renal Replacement Therapy. 2018; 4: 30.

How to cite this article: Sung Jin Bae, Sun Hwa Lee, Seong Jong Yun, Keon Kim. Usefulness of the blood urea nitrogento-serum albumin ratio as a prognostic indicator of severity in acute ischemic stroke. Signa Vitae. 2021;17(4):163-170. doi:10.22514/sv.2021.028. 